\title{
Change of Heart: Two Companies that Transformed Cardiac Care
}

\author{
John Seaberg
}

KEYWORDS: Health Care \& Biotech, Entrepreneurship, Innovation.

One of the benefits of achieving "late middle age" with a relatively intact brain is the perspective one has after participating in an industry for 40 years. My industry background has been primarily in cardiovascular medical devices, where l've worked for a Fortune 500 (Guidant, now Boston Scientific) and co-founded Acist Medical, NeoChord Inc and Phraxis Inc.

In that 40-year span l've watched two established companies take entrepreneurial type risk and in the process transform themselves and their respective industries: Scimed Life Systems and Edwards Life Sciences.

They essentially disrupted themselves, and their current customers, rather than waiting for an outside company to do so. Other companies, in healthcare and other industries, can learn much from their stories.

\section{The Scimed Story}

In the mid 1980s, Scimed Life Systems Inc sold cardiopulmonary bypass (CPB) equipment (heart-lung machine and associated disposables) used during openheart surgeries like coronary artery bypass grafting (CABG). CPB enabled the heart to be stopped (i.e. bypassed to the heart-lung machine), so that heart surgeons could operate in a bloodless field and on a motionless heart. It's a great invention that continues to be used today, but sawing open the sternum, spreading the ribs, harvesting a bypass vein from the leg and stopping the heart all make CABG a highly invasive procedure with lengthy post-op recovery times. The key customer for SciMed at the time was the cardiac surgeon and the CPB technician.

In the early 1980's, Scimed CEO Dale Spencer noted that a new procedure was being developed that avoided cracking the chest, harvesting a leg vein and stopping the heart. It was the early days of Percutaneous Transluminal Coronary Angioplasty (PTCA) and it was

being shown that instead of bypassing the clogged artery, you could balloon open the clog itself by deploying a balloon catheter through a small incision in the upper thigh and threading it through the femoral artery into the clogged coronary artery. Spencer made the transformative strategic decision to migrate from being a surgical product's company to being an interventional cardiology company so that he could ride this new wave. Note the following:

- This strategy meant not only that he was switching customers from the surgeon to the cardiologist but also that his new customer would now be taking business from his old/existing customer. Furthermore, his new customer controlled the patient and therefore had the choice of whether to refer the patient to the surgeon or now, to treat the patient himself. In short he was betting the ranch that the new strategy would work because he was potentially burning a bridge with his old customer.

- This transition was carried out in the face of great resistance from the surgeons who claimed that the $30 \%$ restenosis (re-closure of the artery) rate of PTCA proved it to be clinically inferior to bypassing the clogged artery. This turf war is still being waged today, although to a lesser degree as stents and drug-coated stents now augment the interventional approach, resulting in lower restenosis rates. The introduction of PTCA and subsequently balloon-deployed stents has been perhaps the single most transformative change in the history of the cardiology industry. It marked the ascendency of the interventional cardiologist and the end of the era where the cardiac surgeon called all the shots.

- The end result of this successful transformation for Scimed was the 1994 acquisition of Scimed by Boston Scientific for $\$ 865$ million, one of the 
largest med-tech deals of its era. Today, the Boston Scientific Interventional Cardiology division (the old Scimed) employs 5000 people in Minnesota.

\section{The Edwards Life Sciences Story}

Since its founding in 1951, Edwards Life Sciences has been primarily focused on the heart, specifically surgically placed artificial valves. Today they are the largest provider of prosthetic tissue valves in the world. As such, their primary customer is the cardiac surgeon. The surgical placement of valves requires sternotomy, CPB and opening the heart chamber itself to access and replace the native valve. It is a life-saving procedure, but like CABG, highly invasive -- so not every patient who needs a new valve can tolerate the surgery. This leads to the sad reality that some patients are "sent home to die."

In 2003, Edwards, under the leadership of CEO Mike Mussalem, acquired early-stage PVT (Percutaneous Valve Technologies) Inc. PVT was the first company in the emerging field of valves being placed interventionally rather than surgically. This "valve on a catheter" concept was met with skepticism by the surgeons, but even they had to admit that it was a worthwhile option for patients previously deemed inoperable. And Edwards, like Scimed before it, risked alienating its key customer, the cardiac surgeon, by embracing a new strategy that would send patients to the interventional cardiologist rather than the surgeon.

The defense of this strategy, as stated by Mike Mussalem, was that "someone was going to develop this technology and Edwards was best equipped to do so given its existing core competencies in the valve space." Clearly it was a decision to be strategically focused on the disease rather then the doctor treating the disease.

The outcome of the decision to transform their product line and their customer base was as follows:

- TAVI (transfemoral aortic valve implantation) devices and procedures have dramatically altered the landscape of the structural heart space

- After a lengthy struggle to get FDA approval for use on "inoperable" patients, the company was recently approved for use on "high risk" patients and will soon begin a study for "moderate risk" patients.

- Edwards stock price prior to the PVT purchase was roughly $\$ 4$ a share and climbed steadily as early results of its initial FDA study on its TAVI product began showing up. Today the stock trades at around $\$ 100$ a share, a 25 -fold return over the 12 years since the PVT deal.

\section{Key Takeaways:}

1. Transformative leadership requires courage born of strong conviction that you are leading the company in a better direction.

2. Disruptive technologies only succeed if they are truly a better solution to an unmet clinical need.

3. Disrupting your customer base, while risky, doesn't necessarily mean your old customers will abandon your company. Clear, compelling communication with the surgeons allowed Edwards to maintain its surgical valve business while innovating toward the cardiologist.

Additional Search Terms: Health sciences, medical technology, health technology, disruptive innovation 